\title{
Women Scholars' Experiences with Online Harassment and Abuse: Self-Protection, Resistance, Acceptance, and Self-Blame
}

\author{
George Veletsianos \\ Shandell Houlden \\ Jaigris Hodson \\ Chandell Gosse
}

\begin{abstract}
Although scholars increasingly use online platforms for public, digital, and networked scholarship, the research examining their experiences of harassment and abuse online is scant. In this study, we interviewed 14 women scholars who experienced online harassment in order to understand how they coped with this phenomenon. We found that scholars engaged in reactive, anticipatory, preventive, and proactive coping strategies. In particular, scholars engaged in strategies aimed at self-protection and resistance, while often responding to harassment by acceptance and self-blame. These findings have important implications for practice and research, including practical recommendations for personal, institutional, and platform responses to harassment, as well as scholarly recommendations for future research into scholars' experiences of harassment.
\end{abstract}

Veletsianos, G., Houlden, S., Hodson, J., Gosse, C. (in press). Women Scholars' Experiences with Online Harassment and Abuse: Self-protection, Resistance, Acceptance, and Self-Blame. New Media \& Society.

This is a post-peer review version of the article. The publisher's copy is available at https://doi.org/10.1177/1461444818781324 


\section{Women Scholars' Experiences with Online Harassment and Abuse: Self-Protection, Resistance, Acceptance, and Self-Blame}

Scholars use online platforms such as blogs, Twitter, and Facebook for a diverse assortment of personal and professional purposes such as maintaining contact with colleagues and family members, sharing their research, teaching, conducting public scholarship, and engaging in advocacy and activism (Manca and Ranieri, 2015; Veletsianos, 2016). Scholars' online practices are often met with optimism and highlighted as desirable. Yet, while many researchers are hopeful about the potential positive impacts that scholars' online presence may engender (e.g., Brady, Holcomb and Smith, 2010; Gruzd, Staves and Wilk, 2012; Mbatha, 2014; Thelwall, 2002), concerns around social media use have also been reported in the literature. These include tensions around scholars' use of time, commercialization, establishing personal and professional boundaries, and perceived usefulness or lack thereof (Friesen and Lowe, 2012; Jordan and Weller, 2018; Veletsianos and Kimmons, 2013).

One negative phenomenon that remains understudied is that of faculty harassment online, and specifically women scholars' harassment. Though there is increasing concern over the incivility, abuse, and vitriol facing scholars online (e.g., Cassidy, Faucher and Jackson, 2014; Vera-Gray, 2017), little empirical research examines the experiences of women scholars with online harassment. As the American Association of University Professors notes (AAUP, 2017), online abuse has become an increasingly concerning issue, particular at a historical moment of intensifying ideological division in the U.S. and beyond. As scholars are encouraged to be online as part of their jobs, or want to be online for a variety of scholarly purposes such as knowledge mobilization, the harassment that women scholars face online becomes an important issue to study. Online harassment seeks to silence and marginalize women scholars' voices, and 
adversely impacts not just women's personal and professional lives but also the public's access to scholarship. This comes at a time when online abuse more generally has garnered widespread media coverage as revealed through movements such as \#metoo and \#timesup. We address this identified gap in the literature by reporting on the ways that fourteen women scholars coped with this phenomenon. We first review literature relevant to this topic. Next we present the methods used to conduct this investigation. Finally, we report the results of this study and discuss its practical and scholarly implications.

\section{Review of Relevant Literature}

Little is known about the topic of faculty harassment online, and much less is known about the experiences of women scholars online, specifically. Researchers often assume that scholars' online participation is egalitarian (Veletsianos \& Kimmons, 2016) and often suggest that scholars' online experiences may be the same regardless of gender, race, religion, ethnic origin, ability, age, and so on. Yet, women are more likely than men to report being harassed online (Hess, 2014), and are more than twice as likely to experience severe forms of abuse such as stalking or sexual harassment (Angus Reid, 2016). Citing a 2014 Pew survey, Fox, Cruz, and Lee (2015: 436) note "women report greater emotional distress as a result of online harassment, indicating that their experiences are particularly insidious and likely qualitatively different than those of men." Women who are in the public eye or who use technology to promote their work such as scholars - are placed at even greater risk (Duggan, 2014). Nevertheless, empirical evidence describing women scholars' experiences with online harassment is lacking.

In response to the dearth of literature on the subject, many scholars have recently called for further research into the severity, prevalence, and nature of harassment against women (e.g., Henry and Powell, 2016; Mantilla, 2013; Megarry, 2014; Vitak, et al., 2017). As Vera-Grey 
(2017: 65) observes, such research is especially urgent because women's increased Internet usage intersects with "the continual development of new tools for online social networking," thus creating "greater opportunities for sexist harassment." Our research seeks to fill in some of these gaps.

In two recent large-scale surveys conducted in the United States it was reported that over $40 \%$ of surveyed Internet users experienced some form of online abuse (Duggan, 2014; Lenhart, Ybarra, Zickuhr and Price-Feeney, 2016). A similar survey found that $31 \%$ of Canadian social media users had experienced online harassment (Angus Reid, 2016). These numbers may be much larger as researchers use "different definitions, operationalizations, and cut-off criteria" (Staude-Müller Hansen and Voss, 2012: 261). Moreover, as Scaraduzio, Sheff and Smith (2017) observe, these definitions evolve with the development of new harassing behaviours. Indeed, while the prevalence of abusive behavior online is indisputable, a recent Pew survey (2018) indicates that what counts as abuse (or harassment), and how severe abuse must be before requiring intervention, is much less clear cut. Yet, in all three of the above cited surveys, respondents who had experienced harassment reported emotional distress and fear. As Citron (2014: 3) suggests, “threats of violence, privacy invasions, reputation-harming lies, calls for strangers to physically harm victims, and technological attacks" should be regarded as intentional acts to inflict harm, not merely as harmless comments.

While the scholarly literature focusing on the online harassment of women is growing (Eckert, 2017), little attention is paid to the experiences of women scholars. Previous literature on online harassment has focused on cyberbullying, especially of youth (Tokunaga, 2010; Willard, 2006; Ybarra et al., 2006), online domestic and inter-relational violence (Borrajo, Gamez-Guadix and Calvete, 2015; Henry and Powell, 2015a, 2016), and online feminist spaces 
(Clark-Parsons, 2017). In the context of higher education, most research has focused on the experience of students (rather than faculty), with particular emphasis on the prevalence of cyber bullying (Faucher, Jackson and Cassidy, 2014; Schenck and Fremouw, 2012). While a number of accounts of women in academia experiencing harassment appear in the wider scholarly literature (Citron, 2014; Jane, 2017), only a handful of studies focus exclusively on women scholars. This even as online gender-based harassment is more visible in mainstream media, and women come forward with their experiences of harassment as scholars online. Backlash toward scholars at the time of writing seems to be connected to polarizing sociocultural and sociopolitical issues as evidenced by the experiences of scholars such as that of Professor Beard who received a deluge of abusive comments in response to her work on immigration (Dowell, 2013) and diversity (Boseley, 2017). Furthermore, scholars of new media and videogames have noted disturbing patterns in the gendered nature and content of online harassment. Barak (2005: 78) notes that "gender harassment in cyberspace is very common," a point reiterated in Poland's more recent scholarship (2016) where she argues that online spaces are fraught with vitriol against women.

In addition to women being more likely to experience severe and sustained forms of online abuse (Duggan, 2014), the types of harassing comments women receive are often qualitatively different than those directed to men. Women are more likely than men to receive insults and abuse based on physical appearance, and are more than twice as likely to be sexually harassed online (Angus Reid, 2016; Duggan 2014). Such experiences and findings echo the results of studies of offline harassment; for example, an American Association of University Women survey (2001) shows that while both genders experience sexual harassment, girls experience it with significantly more frequency ( 56 percent vs. 40 percent). In research by Staude-Müller, Hansen, and Voss (2012: 268), which examined stress and online victimization, 
68 percent of respondents reported experiencing sexual harassment online, but with "female respondents being far more strongly exposed." Perhaps unsurprisingly, when scholars go online they are not exempt from the disproportionate amount of abuse faced by women. In a survey of faculty members at one Canadian university, Cassidy, Faucher, and Jackson (2014) uncovered a highly gendered experience of harassment. Female faculty members reported a higher level of online harassment (22\% reported being harassed in the past year compared to $6 \%$ of males), and were much more likely to complete the survey and volunteer for interviews. Most of the harassment these women reported was perpetrated by students or colleagues, and occurred through email, course-related sites, or social media.

The consequences of gendered harassment are significant. In addition to psychological distress, such as fear, shame, or self-loathing for the actions that might have caused the harassment in the first place, women who are the victims of online harassment frequently respond by self-censoring their online participation, deleting their profiles, and generally removing themselves from online spaces (Citron, 2014; Duggan, 2014; Vitak, et al., 2017). These impacts illustrate the critical importance of this issue and its broader social implications: if women curtail their online participation as a result of harassment, the end result is likely a reduction in diversity of thought and opinion in the commons as well as within academia more generally. Indeed, as Salter and Blodgett (2012: 412) note, the "same technologies that appear to offer spaces for shared discourse can just as easily be used for the suppression of political views, and thus can further alienate women." Such critiques are not new; more than a decade ago Barak (2005: 77) suggested that sexual harassment on the internet disrupts its "free, legitimate, functional, and joyful" use. 
Gendered harassment also impacts women's professional lives. In addition to feeling too intimidated to continue participating online, victims describe losing time from work when trying to take legal action, and losing their reputation and employability due to what has been posted about them online. In one example, the repercussions faced by one victim involved "thousands of dollars in legal fees, hundreds of hours of lost work time, [and] the dismantling of [her] chosen career" (Citron, 2014: 10). But the boundaries between the professional and personal are not always clear and can readily be transgressed. In a detailed account of her experiences as a feminist blogger, Hess (2014) explains both the lengths perpetrators go to victimize and disrupt women online, and the consequent amount of time and energy expended in order to achieve redress, but more importantly, to remain safe, as online harassment overflows into the offline world. In another example, Baker (2017) writes about receiving death threats after an interview she gave on MSNBC Live. The anger and fear she experienced as a result of the harassment caused her to "wonder if writing about white supremacy or sexism is worth it," "to wonder if being a woman writer in the internet age is worth the threats and harsh words that follow my work," and especially significantly, to "wonder if it wouldn't be easier to keep [her] head down and [her] mouth shut."

When faced with harassment, online or otherwise, the person who experiences the harassment will tend to adopt one or more strategies to deal with the harassment as a form of coping. We theorize coping by drawing from the basic definition of self-protection from psychological or emotional harm, involving steps taken to mitigate or eliminate stress (Girdano, Dusek and Everly, 1990). In general, women who have experienced harassment engage in coping behaviors that may fall along a framework of avoidance, denial, negotiation, advocacy seeking, and social coping (Knapp et al., 1997; Wasti and Cortina, 2002). Early work on coping by 
Lazarus and Folkman (1984) polarizes coping strategies between problem-focused and emotionfocused, or efforts that aim to ameliorate the circumstances of the abuse contrasted with efforts to avoid, manage or mitigate stress. Left unaddressed in the work of Lazarus and Folkman however, is coping mechanisms that orient toward future stressors, such as the potential for harassment. Scarduzio, Sheff and Smith (2017) interviewed 26 women who had experienced sexual harassment in both online and offline contexts, and discovered that coping strategies could be grouped into three categories: problem-focused, active emotion-focused and passive emotion-focused. Similarly, Schwarzer (2000) offers a nuanced picture of coping structured through four categories: reactive, anticipatory, preventive, and proactive. Reactive coping orients towards already experienced harm; anticipatory coping orients to likely near-future harm; preventive coping orients toward potential though uncertain harm; and proactive coping orients toward goal-management and the accumulation of resources for growth rather than harm or stressors (Biggs, Brough and Drummond 2017). Within workplace settings, such as academia, the question of how to cope with abuse becomes even more complicated as women deal with both professional and personal repercussions of harassment (Shrivastava, 2015).

A small but important body of literature is beginning to explore how female scholars respond in the face of harassment. This is the work by women who self-identify as having been harassed and that then subsequently redirect that harassment into research itself, whether indirectly as the topic of an article or essay, or directly as datasets to be worked with and analyzed. In addition to Hess (2014) and Baker (2017) cited above, we note Hurley's (2016) collection of essays that examine geek culture in relation to gender, misogyny, and online harassment. More explicitly scholarly in nature, Vera-Gray (2017) uses the data from the trolling of her online recruitment call for a project examining street harassment in order to wager a 
feminist position on the added labor endemic to the work of feminist researchers. Campbell's (2017) experiences with trolling of her autoethnographic work also reflects this strategic redeployment of harassment, and Cottom (2015) has taken a similar strategy in using the racist commentary on her widely-read blog as a dataset for sociological analysis. Chess and Shaw (2015) have also used their own experiences with online harassment to critically explore their roles as feminist gaming scholars.

These examples highlight the need for further investigation into the phenomenon of online harassment as well as the lived experiences of those who experience it (Henry and Powell, 2015b). An important thread in this research is to examine the aforementioned reactions to gendered harassment, both online and offline, in order to consider how women scholars cope with such abuse. This is the gap that our research fills. We use Schwarzer's (2000) four categories described above as a theoretical framework to understand scholars' coping strategies. While there is a growing body of literature of sexual harassment coping strategies, there has been no systematic investigation specifically into how female scholars cope with online abuse, even as the studies we've cited above have shown that the impacts of abuse are significant and wideranging.

\section{Methods}

Our goal in this paper is to identify, describe, and make sense of harassment faced by women scholars. With this goal in mind, our research question is: How do women scholars' cope with online harassment?

\section{Participants}

Potential participants were women scholars in various higher education careers and positions, from tenured and adjunct faculty members to university students and independent 
scholars who had experienced online harassment. In other words, the term scholars refers to a diverse group of individuals who engage in scholarly activities beyond faculty members. We directed potential participants to an invitation to participate in this research via two means: first, we emailed all faculty members at one of the authors' institutions. When this resulted in few participants, the invitation to participate in the study was posted on Twitter and Facebook by @AcademicsSay. Others further disseminated this information via standard social media processes (e.g., re-tweeting the Twitter post). More than 100 scholars responded to this call, and fourteen individuals were recruited for interviews.

We interviewed these women in an iterative manner. We started by interviewing six individuals and continued interviewing people until we felt that we had reached a point where we were confident that we could answer our research question using the data collected. This is a common and acceptable method to reach saturation in qualitative research (Baker and Edwards, 2012). In selecting who to invite for interviews out of the individuals who expressed interest in being interviewed, we sought diversity by choosing a range of ages and employment positions (e.g., tenured vs. tenure-track vs. adjunct).

Participants are listed in Table 1. Participants' age ranged from 26 to 70 years of age $($ mean $=42 ; \mathrm{S} . \mathrm{D}=13.78$; median $=36.3)$. At the time of writing, participants were in a wide range of fields, and lived in three countries: the United States of America (11), Canada (2), and the United Kingdom (1). They held a variety of positions: Five were tenured faculty members, and one of these individuals served in an administrative role; three were independent scholars; five were faculty members on fixed-term contracts not on the tenure-track; and one was a librarian. One person held an MA degree, and the rest held a doctorate. All individuals described 
online scholarly activities as being the triggers that resulted in harassment. One individual noted receiving harassing comments in relation to her teaching as well.

\section{--INSERT TABLE 1 ABOUT HERE--}

\section{Data Collection}

Two data sources informed this study: interview transcripts and examples of harassment shared by interview participants. Using a semi-structured interview protocol, we interviewed participants via telephone or Skype. Using this protocol, we asked participants to describe their experiences of online harassment, their reactions to it, the personal and professional impacts of it, the reactions of others to it, and their perceptions of steps that could be taken to mitigate harassment. The semi-structured nature of the interviews allowed us to probe for additional comments on topics that arose. All interviews lasted between 30 and 55 minutes. The interviews were recorded and transcribed verbatim. While some participants did not keep records of harassment they received, others did and and shared those records with us in the form of screenshots (e.g., on Facebook or Twitter). These screenshots were used to triangulate the types of harassment received and participants' responses to it.

\section{Data Analysis}

We (the four researchers) analyzed the interviews and harassment records using an iterative process. We began our inquiry by analyzing the data independently using the same process: we each read the data and wrote open codes to describe experiences of harassment. We used an open coding process partly due to a lack of research focusing on the particular subpopulation of interest, partly because an open coding process enables us to make sense of general characteristics of the phenomenon of interest as it emerges from the raw data, and partly 
because this process allows us to remain open to facets of the experience that can emerge from the raw data without the predetermined categories that are applied in cases of using a preexisting codebook. After each round of independent analysis, we met multiple times to discuss the data and the emerging categories we were seeing in the data. Next, we classified data according to three emerging areas: affect, impact, and response. In exploring, interrogating, discussing, and attempting to confirm/refute these areas, we identified "ways of coping" as a recurring pattern in the data. We then returned to the data and categorized them in ways that described efforts to cope with the experience of harassment. This activity was guided by the constant comparative approach (Glaser and Strauss, 1967) as follows: Two researchers read each piece of data (e.g., a sentence, a full response to an interview question, a screenshot of a social media message) and assigned a code to it describing ways of coping. Next, researchers read the next piece of data (e.g., the next sentence) and compared it to the first generated code. If the code captured the meaning of the data, the data was assigned the code and the researchers moved to the next piece of data. If the code did not capture the meaning of the data, a new code was generated describing the data. The analysis process thus becomes one of constantly comparing the emerging codes to the data. This procedure resulted in a list of codes describing the data. Next, the four researchers discussed the codes and the thematic categories they saw describing codes. We repeated this process until we felt that the data had been saturated and the identified themes captured the ways that participants coped with online harassment.

\section{Rigor}

We took a number of steps to reduce the incidence of biases in the analysis. First, we analyzed data independently in order to avoid influencing each other's interpretations. Second, after analyzing data independently, we discussed our emerging interpretations, identified 
consistent interpretations, asked probing questions of one another, and critiqued our shared understanding of the phenomenon. Third, we analyzed data collaboratively in order to mitigate individual biases. Fourth, we provide "thick descriptions" of results to enable readers to determine whether findings are applicable to their own contexts (Merriam 1995). Fifth, we conducted member checks with participants by emailing them a summary of major findings and asking them to comment on whether findings accurately depicted their experience. Seven of fourteen participants responded and all stated in the affirmative that the findings reflected their experiences and feelings.

\section{Ethical Considerations}

This study was reviewed and approved by an institutional ethics board per the TriCouncil Policy Statement on the Ethical Conduct for Research Involving Humans (Panel on Research Ethics, 2014). Numerous steps were taken to seek free and informed consent; ensure privacy, confidentiality and anonymity; and eliminate undue influence. For instance, audio recordings were erased immediately following transcription; transcriptions and examples of harassment were de-identified; consent was secured digitally prior to the interview and confirmed verbally at the commencement and throughout the interviews; individuals were informed about the potential risks of participating in this project; and participants were provided with an opportunity to review and comment upon draft findings.

\section{Findings}

Coping offers a framework for understanding experiences of harassment, and is useful for understanding the effects of these experiences. In part, this enables an accounting for something that is difficult to quantify as the individual reaction to and understanding of harassment varies significantly. By focusing on coping, we emphasize the individual's subject position and affect 
rather than being beholden to definitions of harassment that may or may not account for the full spectrum of harmful encounters described by the women in the interviews. It is also important to highlight that coping with harassment does not necessarily have a positive outcome that safeguards scholars' well-being. All participants reported negative emotions and many reported feeling fatigued, tired, angry, and anxious. We recognize that coping is a form of emotional labor (Hochschild, 1983), and as such can be distressing in itself, even in the cases of relatively positive outcomes (Wharton, 2009).

Supporting previous findings on coping after harassment (Scarduzio, Sheff and Smith, 2017; Schwarzer, 2000), our data suggests that coping breaks down into multiple categories, many of which overlap, which is to say that the use of one coping strategy does not preclude the use of another, even if apparently contradictory in approach or outcome. As mentioned earlier, we draw on a coping rubric that accounts for reactive, anticipatory, preventive, and proactive coping, thereby addressing the different temporal aspects of the strategies used by women (Schwarzer, 2000). We categorized coping strategies based on individual responses and what those responses suggest about an interviewee's orientation toward the harassment. This accounts for potentially conflicting coping strategies as these strategies are employed with different ends in mind. Significantly, the most common coping strategies were reactive in nature, with some anticipatory and preventive measures taken. The main coping themes that emerged were selfprotection, resistance, acceptance, and self-blame (Table 2). We describe each of these categories below.

\section{-- INSERT TABLE 2 HERE---}

\section{Self-protection}

The single most dominant category of coping which unified a set of responses from 
interviewees were practices of self-protection. All participants described strategies enacted as modes of self-protection and 102 interview excerpts were coded as such. Self-protection took the form of a cluster of behaviors that occurred before, during, and after harassment. In other words, self-protection encompasses a temporal dimension. Reactive self-protection sought to reduce exposure to and impact of ongoing harassment. Anticipatory self-protection sought to reduce the vulnerability to potential harassment, and preventive self-protection sought to eliminate harassment altogether. The reduction of vulnerability and exposure to harassment, while related, are two distinct orientations towards harassment. In the former, interviewees emphasized strategies that center defensive prevention of harassment predicated on knowledge of the possibility or likelihood of harassment. This took shape in the form of engaging in activities like compartmentalizing professional and personal online identities, refining security settings, avoiding of certain social media platforms, broadening of work networks, and turning to silence. Silence manifested as both a kind of refusal to participate, as in Zoe's uncertainty or feeling "gun shy" about continued writing and public engagement on controversial topics, as well as refusal to share personal histories, as in Jasmine's decision to refrain from informing colleagues within her field about the online abuse perpetrated by scholars within their community. In both cases, as with other examples, the targeted women weighed the risk of potential violence and backlash against their desires for justice or rightness. The reduction of exposure to ongoing harassment was less future- or possibility- oriented (ie., it wasn't about potential harassment) and instead covered ways to manage harassment as it was already occurring. This management included strategies such as blocking and ignoring, deleting comments, as well as outsourcing the reading of comments or management of one's account to a loved one in order to avoid seeing comments. Beyond these two groups of strategies, there was also a common expression of efforts to 
reduce the impact of ongoing harassment, to reduce harassment more generally, as well as to eliminate it altogether. As reactive coping strategies, the reduction of harassment's impact typically fell into two streams, one which provided a kind of emotional buffering such as with humor and sarcasm. Abby wryly noted that:

On a good day, I can laugh about it. You know, I mean, the sheer ignorance and absurdity of some of them [the comments] are boggling. You know, you wonder how do you make it through the day if these are the reasoning skills you are working with?

Another form of emotional buffering worked to disavow the impacts by focusing on work, refusing to worry about harassment, and more broadly to simply move on. Interestingly, Jasmine noted that for the sake of her career, she sometimes felt to some degree obligated to "play along" with known harassers out of fear of reprisal and thus made her feel as though she was compromising her integrity. The difficult vulnerability of her position suggests that online harassment of female scholars is perpetrated not only by anonymous users, but also by people known to the target. As such, the impact of online harassment in some instances echoes the impact seen in the currently ongoing (2017-2018) media exposure of powerful men harassing and assaulting women actors, celebrities, and journalists alike, and reflects research that examines the role of technology in domestic abuse. Reactive coping strategies for the reduction of harassment more generally included the understanding to "not feed the trolls," refusal to engage online, and to defuse difficult or inflammatory situations. Attempts to eliminate harassment reflect a more preventive orientation, and relied both on a sense of individual responsibility, as in self-censorship and holding back, as well as a turn toward outside forces for intervening aid, such as in reporting harassment to social media platforms as well as to the police. 


\section{Resistance}

Next to self-protection, all interviewees engaged in resistance, which is a term we use here to describe scholars' refusal to accept or remain silent or passive in response to harassment. Fifty-four interview excerpts were included in this theme. Resistance is a reactive coping strategy and strategies in this theme included persistent attempts at dialogue, persistence more generally, asserting one's voice and authority, turning toward community, and the use of selfprotection. Interviewees noted that in spite of risks of abuse, they desired to continue using social media and to engage in dialogue, even with online users that might not be responsive. For Zoe, this also included writing publicly about her experience with online harassment as a means to open up discussion about the abuse of women scholars online. Relatedly, eight interviewees acknowledged the need to persist more generally in the face of abuse. Jasmine framed it thusly: "I am not quitting. I've been at this too long to throw it out the window just because someone with a Y chromosome thinks that they get to throw some sort of fit, and I'm just gonna disappear off the face of the planet." In other words, it was not simply about expanding or maintaining open discourse, but that given the discouraging reality of being a woman online, continuing scholarly work and teaching in itself required determination and resilience. As such, simply continuing became an act of resistance.

While asserting one's voice might at first appear to simply belong with the desire to engage in dialogue, responses in this category relied on a willingness to engage more aggressively than those that emphasized shared dialogue. For example, some women framed their own responses as speaking out, calling out, and trolling back. Lucy understood it as fighting "the good fight." In each instance, the woman in question turned more actively towards using her voice, rather than the back and forth of speaking and listening as in dialogue. Olivia, for 
example, initially responded by blocking, but eventually began to troll back, to find "ways to kind of mock or find humor in it." Another strategy that emerged was the willingness to share their experiences with others, be they family, friends, colleagues, or students. Though sharing might not typically be seen as a form of resistance, by not remaining silent and developing community around shared experiences, women were able to push back against harassment. Stella shared her experience with her students, family, and a colleague "who was equally if not more pissed off" than she was, which helped validate her feelings about the experience. This development of community as resistance was especially prominent for women who spoke with other women or chose to work with female mentors or colleagues with more regularity. The final significant strategy within resistant-type responses was that of self-protection. Self-protection strategies have been discussed at length above, but for the purposes of resistance, they also take the form of refusal to engage the voices of abusers as a way for women to continue their online participation in safer and more doable terms.

\section{Acceptance}

Another significant theme that emerged was tied to responses that suggested acceptance of the problem. This theme represents the recognition that the problem of harassment was unlikely to go anywhere any time soon, and thus coping strategies focused on emotional responses to harassment. Nine participants were included in this theme, and twenty-five interview excerpts were coded as such. The strategies included here were primarily reactive coping strategies. Again, many of the responses within this category can also be tied to other themes; for example, self-censorship and increased privacy settings are modes of self-protection, but they are also behaviours suggestive of a recognition that online harassment could happen again in the future. In other words, self-protection and acceptance are at times two sides of the 
same coin. Further examples include blocking and ignoring, avoiding use of social media to avoid the potential for harassment, continuing use of social media but in ways that minimize the effects of harassment (e.g., ignoring abusive comments), feeling unsurprised by the advent of harassment, feeling the need to move on or not to worry about it, and feeling a general sense of acceptance itself. Hannah, for example, suggested that harassment is something "you just have to get used to... It almost seems like it's the price to pay if you want a voice in things, and you're going to have to learn to get over it." It should be noted that acceptance is by no means necessarily a statement of being complacent with or condoning harassment, but instead reflects a feeling that there are few opportunities for immediate and decisive change. As Lucy suggests, ... it's kind of almost like, there's a phrase for this, where you're just sort of used to it because it's happened so many times and you share it. It doesn't even bring you closer to women anymore because you're just like yeah, great, that happened again, cool, like the sun came up.

\section{Self-blame}

The last theme that emerged was that of self-blame, in which eight participants in eighteen coded excerpts described how they felt they needed to compromise their own values, had to apologize and monitor their own behavior, and most commonly, minimize their experiences of harassment. This latter response of minimization was mentioned even by women whose harassment could readily be described as extremely abusive. In a clear example of minimization, Jessica said that, "compared to some of the other people who got harassed, mine was relatively minor," even though she received death threats and was doxed. In another case, Jasmine so regularly received online harassment that during her interview she limited her discussion to some of the more egregious violations; general comments about physical 
appearance, while annoying, were not as problematic as solicitations for sex or intimidation, for instance. Another common thread that emerged was that some women felt that to some degree they were responsible because they were naïve about how social media and online engagement actually work. These kinds of self-blame and minimization are best characterized as emotional responses to the abuse, and as such, are forms of reactive coping.

\section{Discussion and Implications}

The women who were interviewed for this study coped with online harassment by engaging primarily in reactive, problem-focused coping like self-protection and resistance, and emotion-focused coping, like acceptance, and more negative experiences like self-blame. No single individual engaged in one single strategy, while nearly all of them engaged in at least two of these approaches to coping with harassment. These coping approaches are similar to the coping expressed by women who experience more general forms of harassment, as detailed in prior literature (Knapp et al., 1997; Lazarus and Folkman, 1984; Scarduzio, Sheff and Smith, 2017; Schwarzer, 2000; Wasti and Cortina, 2002). By using coping as the framework of analysis, we address the concerns of numerous scholars who insist on the need for further research in the effects of online abuse on women (Henry and Powell, 2016; Mantilla, 2013; Vitak, et al., 2017). Moreover, by centering coping as a form of emotional labor, this research makes visible the hidden labor (Vera-Gray, 2017) often associated with gendered experience online, thus contributing to a body of literature that examines the impact of gendered harassment in online spaces and works to make legible structure inequalities therein (Cassidy, Faucher and Jackson, 2014; Citron, 2014; Jane, 2017; Mantilla 2017; Salter and Blodgett, 2012).

These findings have meaningful implications for practice and research. First, this research adds much-needed insight to the extant literature on women scholars' experiences of 
online harassment. While the current literature includes a number of personal accounts of women scholars facing harassment (e.g., Chess and Shaw, 2015; Cottom (2015), this study develops broader account harassment across a number of scholars. Yet, the findings reported here are reflective of the broader literature describing the way that women overall experience and respond to harassment (Scarduzio, Sheff and Smith, 2017). Study participants expressed the range of avoidance, denial, negotiation, advocacy seeking, and social coping strategies detailed in Knapp et al. (1997) and Wasti and Cortina (2002). These findings thus show that women scholars cope with harassment in ways that are consistent with how women in general cope with it, although scholars may face institutional and peer pressures to be online due to their work. Given the findings of this study, future research might inquire deeper into particular experiences of abuse or examine the prevalence of this issue, especially with regards to the frequently gendered nature of this abuse. For instance, researchers may ask: What is the lived experience of particular types of online abuse (e.g., being doxed, sexual harassment, rape threats), and how does the emotional labor required to navigate such experiences compare with other forms of emotional labor required by academia and scholarly work? What personal, institutional, or platform strategies result in mitigating harassment and its effects? What proportion of women scholars face online harassment, and how does the type of harassment women scholars face compare to their male counterparts? Who is harassed, in what ways does that harassment differ based on a variety of factors (e.g., demographics, academic rank), and why? What are the outcomes associated with typical coping strategies that scholars engage in?

Second, the potential of social media being used for harm and abuse needs to be accounted for into any expectations, institutional or otherwise, placed on social media uptake in higher education. While online participation in higher education contexts is often seen positively, 
and scholars are regularly encouraged to engage in public and networked scholarship (cf Veletsianos 2016), this research highlights the potential and far-reaching consequences that some women scholars experience when they go online. In practical terms, higher education institutions must acknowledge this potential, resist the pressure to create an overwhelmingly positive depiction of online platforms when encouraging scholars to "go online," and take steps to prepare scholars to face unsavory audiences. Future research focusing on this area could investigate the different ways that scholars face pressures to go online as well as examine whether and how institutions of higher education acknowledge and respond to instances of online harassment.

Third, this research shows that higher education institutions need to provide training for navigating social media both as representatives of the institutions and as public intellectuals. At a basic level, universities need to be clear about their position on public scholarship and how that will affect how they support harassed faculty. Such support should first be reflected in harassment prevention measures, which on a practical level should include training and resources to develop self-protective abilities, including familiarizing scholars with things like two-factor identification, password management systems, and how to employ applications developed to mitigate the onslaught of harassment. This kind of training will emphasize anticipatory and preventative coping techniques. It should also include awareness campaigns around what kind of work is targeted for harassment and what this harassment typically might look like. This too is another area ripe for future research. For example, the risks surrounding public engagement of particular content (feminist, critical race etc.) and particular research agendas, and the varying nature of targeted harassment should be determined, so that the potentially impacted scholars are prepared and supported. In other words, future research should identify root causes of and types 
of content that trigger harassment, and ideally, such research should emphasize continued public engagement. Additionally, research into training and resources in the event of harassment, such as support networks for victims, as well as training for colleagues of victims, would be useful. This, in other words, will be a form of institutionalized anticipatory coping that facilitates effective reactive coping.

Fourth, as the previous paragraph highlights, our research shows that self-protection will not solve the problem. No matter the steps taken by individuals to prevent harassment, public scholarship on social media comes with risk. Moreover, self-protection is a form of emotional labor that may result in fatigue and withdrawal from public discourse, and future research should attend to this reality (Vera-Gray, 2017). If the alternative to harassment is silence, higher education institutions, as well as social media platforms, have an obligation to respond to this problem - the onus cannot be entirely on victims or women more generally lest they become overburdened and isolated. Significantly, we strongly recommend that women and other targeted groups need to be involved in decision-making, software development/consulting, and policydevelopment as it their experiences will inform how to respond, and hopefully resolve, the problem of harassment. Fundamentally, institutions should be clear about what steps both the individual might and the institution will take in the instance of online harassment, and these steps need to be developed with the insights of those who have experienced harassment.

Fifth, this study highlights the agency and strength with which these women scholars confront vitriol and abuse. Considering the broader environment that these scholars find themselves in (i.e. an environment in which institutional supports were mostly absent, social media platforms did little to curtail it, and the broader culture accepts it), the story of scholars facing harassment is not just a story of abuse, intimidation, and caution, but it is also a story of 
strength, courage, and determination, much as the research that utilizes experiences of online abuse shows (Campbell, 2017; Chess and Shaw, 2015; Cottom, 2015; Vera-Gray 2017). This finding stands in contrast to editorials and advice columns recommending to scholars to "watch what they say" online (Donoghue, 2015; Pryal, 2015). In investigating this phenomenon, we recommend that future researchers further investigate courageous practices of resistance and defiance, and shine more light upon the strength women scholars exhibit when faced with harassment.

Sixth, it is important to highlight that even though this study presents a first step in a broader examination of targeted harassment against women scholars, the field will benefit from research that examines subpopulations of scholars targeted for harassment and make relevant recommendations. For example, in analyzing her own experiences of harassment Cottom (2015) theorizes the relationship between race and abuse as something different for black women. Cottom's experiences vividly point out the ways in which gender and race mediate individuals' experiences of online participation. As an example to how the results of this study could be further interrogated, consider the finding that women scholars resist harassment by persisting in their efforts. Researchers need to investigate whether the notion of resistance to harassment necessarily holds true for scholars across demographics. Who engage in resistance and who do not? Why do some resist and others don't? Do white scholars, scholars of color, and transgender scholars resist in the same ways? Whose methods of resisting are deemed "acceptable" and whose are not, and in what ways are acceptable methods of resisting intersecting with scholar demographics? Furthermore, any training on this topic should not just address gender but ultimately race, sexuality, and so on, as well as examine and identify the specific ways various groups are targeted. 
Finally, it is important to note that this study faces a number of limitations. The data are drawn from participants residing in affluent, English-speaking, and western nations, and may not necessarily be representative of the experiences of those scholars facing dissimilar contexts. Moreover, we do not report on how scholars' experiences may differ in relation to demographics, academic positions, digital platforms, locations, or areas of expertise. Gender is not the only factor that shapes harassment and its frequency and severity, and future research should further interrogate how online harassment is experienced differently by different subject positions. By design, this study does not aim to examine the prevalence of harassment nor does it make comparisons regarding the prevalence of harassment toward specific groups, or capture all the ways that individuals cope with and respond to harassment. Nevertheless, this study provides the first systematic investigation of how a group of women scholars' cope with online harassment and establishes the groundwork for future research into scholars' experiences of online harassment that addresses the aforementioned limitations.

\section{Conclusion}

While efforts to engage in emerging forms of scholarship that include digital and networked means are often seen with a positive light, this research demonstrates the contested terrain that some female scholars face when they are online. As online harassment adversely impacts scholars and disproportionately impacts women, their institutions, and the societies that scholars seek to serve by mobilizing their scholarship, this phenomenon is significant to study. While instances of women facing harassment and abuse have been reported in the broader literature examining online spaces since the early 1990's, this study reveals a variety of ways that female scholars use to cope with it. Beyond gaining an understanding of this phenomenon, we urge academics, faculty trainers, administrators, technology companies, and policymakers to use 
the recommendations provided herein to take steps to not only support scholars who are facing harassment, but also take steps to mitigate the incidence of this phenomenon.

Acknowledgements: This research was supported by the [redacted] 


\section{References}

Angus Reid (2016) Trolls and tribulations: One-in-four Canadians say they're being harassed on social media. Available at:http://angusreid.org/wp-content/uploads/2016/ 10/2016.10.04-Social-Media.pdf (accessed 10 February 2018).

American Association of University Professors (2017) An In-Depth Look at Targeted Harassment of Faculty. One Faculty One Resistance. Available at: https:// onefacultyoneresistance.org/faculty-attack-fighting-targeted-harassment/ (accessed 22 January 2018)

Baker KJ (2017) Furious but Frightened. In Women in Higher Education. Available at: https://www.wihe.com/article-details/47/furious-but-frightened/ (accessed 23 February 2018).

Barak A (2005) Sexual harassment on the internet. Social Science Computer Review 23: 77-92.

Biggs A, Brough P and Drummond S (2017) Lazarus \& Folkman's psychological stress and coping theory. In: Cooper C L and Campbell Quick J (eds.) The Handbook of Stress and Health: A Guide to Research and Practice. Chichester: John Wiley \& Sons, Ltd. pp. $349-364$.

Boseley S (2017) Mary Beard abused on Twitter over Roman Britain's ethnic diversity. In The Guardian. Available at: https://www.theguardian.com/uk-news/2017/aug/06/mary-beardtwitter-abuse-roman-britain-ethnic-diversity (accessed 23 April 2018).

Borrajo E, Gámez-Guadix M and Calvete E (2015) Cyber dating abuse: Prevalence, context, and relationship with offline dating aggression. Psychological Reports 116: 565-585.

Brady KP, Holcomb LB and Smith BV (2010) The use of alternative social networking sites in higher educational settings: A case study of the e-learning benefits of Ning 
in education. Journal of Interactive Online Learning 9(2): 151-170.

Campbell E (2017) “Apparently Being a Self-Obsessed C**t Is Now Academically Lauded": Experiencing Twitter Trolling of Autoethnographers. Forum Qualitative Sozialforschung /Forum: Qualitative Social Research 18(3).

Canadian Institutes of Health Research, Natural Sciences and Engineering Research Council of Canada, and Social Sciences and Humanities Research Council of Canada (2014) TriCouncil Policy Statement: Ethical Conduct for Research Involving Humans. Retrieved on Apr 19, 2018 from http://www.pre.ethics.gc.ca/pdf/eng/tcps22014/TCPS_2_FINAL_Web.pdf

Cassidy W, Faucher C and Jackson, M (2014) The Dark Side of the Ivory Tower: Cyberbullying of University Faculty and Teaching Personnel. Alberta Journal of Educational Research 60(2): 279-299.

Chess S and Shaw A (2015) A Conspiracy of Fishes, or, How We Learned to Stop Worrying About \#GamerGate and Embrace Hegemonic Masculinity. Journal of Broadcasting \& Electronic Media 59(1): 208-220.

Citron DK (2014) Hate Crimes in Cyberspace. Cambridge, MA: Harvard University Press. Clark-Parsons R (2017) Building a digital Girl Army: The Cultivation of feminist safe spaces online. New Media \& Society. Epub ahead of print 6 October 2017. DOI: $10.1177 / 1461444817731919$

Cottom T M (2015) “Who Do You Think You Are?”: When Marginality Meets Academic Microcelebrity. Ada: A Journal of Gender, New Media, and Technology 7. Donoghue F (2015) \#WatchWhatYouSay. The Chronicle of Higher Education, 28 September. 
Available at: http://chronicle.com/article/WatchWhatYouSay/233405 (accessed 12 February 2018).

Dowell B (2013) Mary Beard suffers 'truly vile' online abuse after Question Time. In The Guardian. Available at: https://www.theguardian.com/media/2013/jan/21/mary-beardsuffers-twitter-abuse (accessed 23 April 2018).

Eckert S (2017) Fighting for recognition: Online abuse of women bloggers in Germany, Switzerland, the United Kingdom, and the United States. New Media \& Society. Epub ahead of print 29 January 2017. DOI: 10.1177/1461444816688457

Faucher C, Jackson M, and Cassidy W (2014) Cyberbullying among University Students: Gendered Experiences, Impacts, and Perspectives. Education Research International 2014: $1-10$.

Fox J, Cruz C and Lee JY (2015) Perpetuating online sexism offline: Anonymity, interactivity, and the effects of sexist hashtags on social media. Computers in Human Behavior 52: $436-442$.

Friesen N and Lowe S (2012) The questionable promise of social media for education: Connective learning and the commercial imperative. Journal of Computer Assisted Learning 28(3): 183-194.

Girdano D, Dusek D and Everly G (1990) Controlling Stress and Tension. London: Pearson.

Glaser BG and Strauss AL (1967) The discovery of grounded theory. Chicago: Aldine Publishing.

Gruzd A, Staves K and Wilk A (2012) Connected scholars: Examining the role of social media in research practices of faculty using the UTAUT model. Computers in Human 
Behavior 28(6): 2340-2350.

Henry N and Powell A (2016) Technology-Facilitated Sexual Violence: A Literature Review of Empirical Research. Trauma, Violence \& Abuse. 1-14.

Henry N and Powell A (2015a) Beyond the 'sext': Technology-facilitated sexual violence and harassment against adult women. Australian \& New Zealand Journal of Criminology 48 (1): 104-118.

Henry N and Powell A (2015b) Embodied Harms: Gender, Shame, and Technology-Facilitated Sexual Violence. Violence Against Women 21(6): 758-779.

Hess A (2014) Why women aren't welcome on the Internet. Pacific Standard, 6 January. Available at: https://psmag.com/why-women-aren-t-welcome-on-theinternet-aa21fdbc8d6 (accessed 16 January 2018).

Hochschild AR (1983) The Managed Heart: Commercialization of Human Feeling. Berkeley: University of California Press.

Jane E (2017) Misogyny Online: A short and brutish history. Thousand Oaks: Sage.

Jordan K and Weller M (2018) Academics and Social Networking Sites: Benefits, Problems and Tensions in Professional Engagement with Online Networking. Journal of Interactive Media in Education 2018(1): 1.

Knapp DE, Faley RH, Ekeberg SE and Dubois CL (1997) Determinants of target responses to sexual harassment: A conceptual framework. Academy of Management Review 22(3): 687-729.

Lazarus R and Folkman S (1984) Stress, appraisal, and coping. New York: Singer Pub. Co.

Lenhart A, Ybarra M, Zickuhr K and Price-Feeney M (2016) Online Harassment, Digital 
Abuse, and Cyberstalking in America. Report for Data \& Society Institute. Report no. 11.21.16, 2016. New York: Center for Innovative Public Health Research. Retrieved from: https://datasociety.net/output/online-harassment-digital-abuse-cyberstalking/ (accessed 28 February, 2018).

Manca S and Ranieri M (2015) "Yes for sharing, no for teaching!”: Social Media in academic practices. Internet and Higher Education 29: 6-74.

Mantilla K (2013) Gendertrolling: Misogyny adapts to new media. Feminist Studies 39(2): $563-570$.

Mbatha B (2014) Global Transition in Higher Education: From the Traditional Model of Learning to a New Socially Mediated Model. The International Review of Research in Open and Distance Learning 15(3): 257-274.

Megarry J (2014) Online incivility or sexual harassment? Conceptualising women's experiences in the digital age. Women's Studies International Forum 47: 46-55.

Merriam S (1995) What can you tell from an $\mathrm{N}$ of 1 ? Issues of validity and reliability in qualitative research. PAACE Journal of Lifelong Learning 4: 51-60.

Pew Research Center (2014) Online Harassment. Available at: http://www.pewinternet. org/2014/10/22/online-harassment/ (accessed 28 February 2018).

Pew Research Centre (2018) Crossing the Line: What Counts as Online Harassment? Available at: http://www.pewinternet.org/2018/01/04/crossing-the-line-what-counts-as-onlineharassment/ (accessed 28 February 2018).

Poland B (2016) Haters: Harassment, Abuse, and Violence Online. Lincoln: Potomac Books. 
Pryal K (2014) Disclosure blues: Should you tell colleagues about your mental illness?

Chronicle Vitae, 13 June. Available at: https://chroniclevitae.com/news/546-disclosure-

bluesshould-you-tell-colleagues-about-your-mental-illness (accessed 18 February, 2018).

Salter A and Blodgett B (2012) Hypermasculinity \& Dickwolves: The Contentious Role of Women in the New Gaming Public. Journal of Broadcasting \& Electronic Media 56(3): 401-416.

Scarduzio JA, Sheff SE and Smith M (2017) Coping and Sexual Harassment: How

Victims Cope across Multiple Settings. Arch Sex Behav 47(2): 327-340.

Schenck A and Fremouw WJ (2012) Prevalence, Psychological Impact, and Coping of

Cyberbully Victims Among College Students. Journal of School Violence 11(1): 21-37.

Schwarzer R (2000) Manage stress at work through preventive and proactive coping. In E. A.

Locke (ed) The Blackwell Handbook of Principles of Organizational Behavior Oxford:

Blackwell, pp. 342-355.

Shrivastava H (2015) Harassment at the Workplace, Powerlessness and Identity: Experiences of Women Civil Servants in India. Indian Journal of Gender Studies 22(3): 437-457.

Staude-Müller F, Hansen B and Voss M (2012) How stressful is online victimization? Effects of victim's personality and properties of the incident. European Journal of Developmental Psychology 9(2): 260-274.

Thelwall M (2002) Research dissemination and invocation on the Web. Online Information Review 26(6): 413-420.

Tokunaga RS (2010) Following you home from school: A critical review and synthesis of research on cyberbullying victimization. Computers in Human Behavior 26(3): 277-287.

Veletsianos G (2016) Networked Scholars: Social Media in Academia. New York: 
Routledge.

Veletsianos G and Kimmons R (2013) Scholars and Faculty Members Lived Experiences in Online Social Networks. The Internet and Higher Education 16(1): 43-50.

Veletsianos G and Kimmons R (2016) Scholars in an Increasingly Digital and Open World: How do Education Professors and Students use Twitter? The Internet and Higher Education 30: 1-10.

Vera-Gray F (2017) 'talk about a cunt with too much idle time': trolling feminist research. feminist review 115: 61-78.

Vitak J, Chadha K, Steiner L and Ashktorab Z (2017) Identifying Women’s Experiences With and Strategies for Mitigating Negative Effects of Online Harassment. In CSCW'17. Portland, OR, 25 February-1 March 2017, pp.1231-1245.

Wasti SA and Cortina LM (2002) Coping in context: Sociocultural determinants of responses to sexual harassment. Journal of personality and Social Psychology 83(2): 394.

Wharton, AS (2009) The Sociology of Emotional Labor. Annual Review of Sociology 35: 147165.

Willard N (2006) Cyberbullying and cyberthreats: Responding to the challenge of online social cruelty, threats, and distress. Eugene: Research Press.

Ybarra ML, Mitchell KJ, Wolak J and Finkelhor D (2006) Examining characteristics and associated distress related to Internet harassment: Findings from the second youth Internet safety study. Pediatrics 118: e1169-e1177. 
Table 1

Participants

\begin{tabular}{|c|c|c|c|c|c|}
\hline Pseudonym & Age & Current Position & $\begin{array}{l}\text { Area of Study } \\
\text { and Practice }\end{array}$ & $\begin{array}{l}\text { Terminal } \\
\text { Degree }\end{array}$ & $\begin{array}{l}\text { Country of } \\
\text { Residence }\end{array}$ \\
\hline Abby & 34 & $\begin{array}{l}\text { Non-tenure-track } \\
\text { academic on a fixed- } \\
\text { term contract }\end{array}$ & Health & $\mathrm{PhD}$ & USA \\
\hline Chloe & 70 & Independent Scholar & Leadership & $\mathrm{PhD}$ & USA \\
\hline Emma & 60 & Tenured Academic & Geology & $\mathrm{PhD}$ & Canada \\
\hline Hannah & 35 & Tenured Academic & $\begin{array}{l}\text { French \& Second } \\
\text { Language } \\
\text { Acquisition }\end{array}$ & $\mathrm{PhD}$ & USA \\
\hline Jasmine & 29 & Independent Scholar & History & MA & USA \\
\hline Jessica & 34 & Librarian & Sociolinguistics & $\mathrm{PhD}$ & USA \\
\hline Lucy & 47 & Tenured Academic & $\begin{array}{l}\text { Molecular } \\
\text { Biology }\end{array}$ & $\mathrm{PhD}$ & USA \\
\hline Magda & 36 & $\begin{array}{l}\text { Non-tenure-track } \\
\text { academic on a fixed- } \\
\text { term contract }\end{array}$ & Physics & $\mathrm{PhD}$ & USA \\
\hline Olivia & 33 & Tenured Academic & Political Science & $\mathrm{PhD}$ & USA \\
\hline Sarah & 55 & $\begin{array}{l}\text { Tenured Academic - } \\
\text { Administrator }\end{array}$ & Education & $\mathrm{PhD}$ & USA \\
\hline Sophia & 60 & $\begin{array}{l}\text { Non-tenure-track } \\
\text { academic on a fixed- } \\
\text { term contract }\end{array}$ & $\begin{array}{l}\text { Human } \\
\text { Resources and } \\
\text { Management }\end{array}$ & $\mathrm{PhD}$ & Canada \\
\hline
\end{tabular}




\begin{tabular}{llllll} 
Stella & 32 & $\begin{array}{l}\text { Non-tenure-track } \\
\text { academic on a fixed- } \\
\text { term contract }\end{array}$ & $\begin{array}{l}\text { Couple and } \\
\text { Family Therapy }\end{array}$ & PhD & USA \\
Stephany & 26 & $\begin{array}{l}\text { Non-tenure-track } \\
\text { academic on a fixed- } \\
\text { term contract }\end{array}$ & Neuroscience & $\mathrm{PhD}$ & UK \\
Zoe & Independent Scholar & $\begin{array}{l}\text { Religious } \\
\text { Studies }\end{array}$ & $\mathrm{PhD}$ & USA \\
& & & & \\
\hline
\end{tabular}


Table 2

Themes describing the ways women scholars cope with online harassment

\begin{tabular}{|c|c|c|}
\hline Theme & Description & Examples \\
\hline Self-protection & $\begin{array}{l}\text { Self-protection refers to a cluster of behaviours that took } \\
\text { place before, during, and after harassment occurred. Its aim } \\
\text { was to reduce exposure to, and impact of ongoing } \\
\text { harassment, to reduce the vulnerability to potential } \\
\text { harassment, and to eliminate harassment altogether. }\end{array}$ & $\begin{array}{l}\text { increased security } \\
\text { settings, avoiding } \\
\text { certain social media } \\
\text { platforms, } \\
\text { outsourcing readings } \\
\text { of comments to } \\
\text { others, self- } \\
\text { censorship }\end{array}$ \\
\hline Resistance & $\begin{array}{l}\text { Resistance refers to scholars' refusal to accept or remain } \\
\text { silent or passive in response to harassment. }\end{array}$ & $\begin{array}{l}\text { speaking out, trolling } \\
\text { back, refusing to } \\
\text { remain silent, } \\
\text { attempting to engage } \\
\text { harassers in dialogue }\end{array}$ \\
\hline Acceptance & $\begin{array}{l}\text { Acceptance refers to the recognition that the problem of } \\
\text { harassment was unlikely to disappear any time soon, and } \\
\text { thus coping strategies were reactive in nature and focused on } \\
\text { emotional responses to harassment. }\end{array}$ & $\begin{array}{l}\text { avoiding social } \\
\text { media, increased } \\
\text { privacy settings, } \\
\text { feeling unsurprised } \\
\text { by harassment }\end{array}$ \\
\hline Self-blame & $\begin{array}{l}\text { Self-blame refers to participants feeling that they needed to } \\
\text { compromise their own values, apologize and monitor their } \\
\text { own behavior, and minimize their experiences of } \\
\text { harassment. }\end{array}$ & $\begin{array}{l}\text { comparing } \\
\text { harassment to others' } \\
\text { experiences, blaming } \\
\text { one's own naiveté, } \\
\text { feeling stupid }\end{array}$ \\
\hline
\end{tabular}

